\title{
MEMÓRIA DE TRABALHO E PRODUÇÃO ORAL DA LINGUAGEM *
}

\author{
PAULA LENZ COSTA LIMA \\ (Universidade Estadual do Ceará) \\ EDSON FRANÇOZO \\ (LAFAPE/IEL/UNICAMP)
}

In this paper, we examine the use of silent pauses made by high and low working memory span individuals, during the reading span test (the Brazilian Portuguese version), aiming at verifying possible strategies used by the subjects in order to accommodate the transient computational and storage demands that occur in the task. Our results are congruent with the idea that language production quality is also influenced by the subjects' working memory capacity: high span subjects produced more sentences without pause, made shorter pauses, and therefore spent less time reading the test sentences than low span subjects.

A capacidade de memória de trabalho parece exercer papel relevante no processamento da linguagem, explicando diferenças entre indivíduos relativamente a vários aspectos da compreensão lingüística (King \& Just 1991; Just \& Carpenter 1992; Miyake et al. 1995). A memória de trabalho tem sido compreendida como um sistema central único responsável pelo processamento e armazenamento temporário de informações na execução de tarefas cognitivas complexas, que competem por um mesmo pool de ativação e cuja capacidade é limitada, podendo variar de indivíduo para indivíduo (Baddeley 1986; Just \& Carpenter 1992).

Just \& Carpenter (1992) defendem a tese de que a natureza da compreensão da linguagem de uma pessoa depende de sua capacidade de memória de trabalho. Como essa capacidade varia de indivíduo para indivíduo na quantidade de ativação que tem disponível para as demandas de computação e armazenamento da linguagem, isso implica diferenças quantitativas e qualitativas entre os indivíduos no que diz respeito à velocidade e exatidão com que compreendem a linguagem. Ou seja, existem diferenças individuais que se devem à capacidade e à eficiência dos processos mentais envolvidos.

Vários experimentos, realizados com indivíduos de capacidade de memória de trabalho diferentes, têm sugerido que essa capacidade é comum aos vários processos envolvidos na compreensão, i.e., engloba acesso lexical, análise sintática, semântica,

\footnotetext{
* Agradecemos o incentivo de Eleonora Cavalcante Albano, desde o início deste projeto. Agradecemos também a Plínio Almeida Barbosa, pelas sugestões que contribuíram para que a análise acústica e o estudo das pausas se aperfeiçoassem. Naturalmente, os erros que persistem no texto, apesar da colaboração deles, são de nossa inteira responsabilidade. Este trabalho teve financiamento da Capes (para Paula Lenz Costa Lima).
} 
pragmática, entre outros, e abre novas discussões sobre resultados que corroboravam a noção de modularidade. Um exemplo é o resultado obtido por Just \& Carpenter (1992) ao replicarem o experimento de Ferreira \& Clifton (1986). Esses autores mediram o tempo de leitura de orações relativas reduzidas do tipo The evidence examined by the lawyer shocked the jury e The defendant examined by the lawyer shocked the jury, para verificar se o que chamam de dica pragmática (o fato de o substantivo inicial ser ou não animado) assinalava a interpretação correta da parte ambígua inicial das sentenças. Os sujeitos foram levados a confundir-se (o chamado garden path effect), apesar da dica pragmática, não apresentando, portanto, diferença no tempo de processamento. Os autores concluíram que a análise sintática é um processo cognitivo modular, encapsulado, no sentido em que é impermeável a outras fontes de informação, e condizente pois com a hipótese da modularidade de Fodor (1983). Just \& Carpenter encontraram outros resultados, com sujeitos previamente classificados como tendo alto ou baixo reading spans. Foram incluídas no experimento dicas sintáticas explícitas através de orações relativas não reduzidas, sintaticamente não ambíguas, do tipo The evidence that was examined by the lawyer shocked the jury e The defendant who was examined by the lawyer shocked the jury. Os autores verificaram que enquanto a dica sintática foi utilizada pelos dois grupos de span, a dica pragmática só foi utilizada pelos sujeitos de alto span. Esses resultados, segundo os autores, contradizem a visão de que o processamento é encapsulado e confirmam que o "encapsulamento sintático" apresentado por alguns sujeitos é melhor explicado em termos de uma restrição da capacidade de memória de trabalho.

Para medir a capacidade de memória de trabalho individual, Daneman \& Carpenter (1980, 1983) desenvolveram a tarefa de Reading span, que envolve os recursos necessários para a compreensão de sentenças, com um componente de armazenamento adicional: enquanto lê em voz alta um grupo de sentenças, o sujeito tem que reter na memória as palavras finais de cada sentença a serem evocadas no final do grupo. Seu formato é semelhante aos dos testes tradicionais de digit e word span, com demandas compatíveis com as características da memória de trabalho, ou seja, os tempos de apresentação são curtos e a quantidade de informação que o leitor deve reter corresponde aproximadamente à capacidade atribuída à memória de trabalho. Como computação e armazenamento concorrem pelo mesmo pool de ativação, a sobrecarga imposta pela tarefa pode prejudicar tanto uma função quanto a outra, uma vez que não há recurso suficiente para execução da tarefa como um todo. Assim, dependendo da capacidade de memória de trabalho do sujeito, o processamento pode ficar mais lento e/ou informações podem ser esquecidas.

Com o objetivo de verificar possíveis pistas acústicas relacionadas às estratégias usadas pelos sujeitos para acomodar as demandas de computação e armazenamento temporário na execução da própria tarefa de reading span, gravamos a aplicação de uma versão adaptada ao português brasileiro com alunos da Unicamp, falantes nativos do português. Ao tentar armazenar informações (as palavras a serem relembradas) e processar (compreender e ler as frases em voz alta) ao mesmo tempo, o sujeito pode utilizar determinadas estratégias que influenciem seu desempenho. Se sua atenção estiver mais voltada para o armazenamento, é possível que haja alguma perturbação na 
leitura, que poderia ser detectada através de uma análise das pausas ou do contorno entoacional das sentenças envolvidas. Se não há perturbação na leitura, é possível que haja uma perda no armazenamento. Pausas longas intra ou interfrases podem significar acomodações entre o armazenamento e a computação.

Não nos propomos, neste trabalho, a analisar todas as possíveis perturbações causadas pela tarefa simultânea de armazenamento e computação, mas apenas a duração da produção das frases, com ou sem pausas silenciosas, e a localização dessas pausas. Somente as pausas silenciosas dentro da sentença são analisadas porque nosso interesse está no fenômeno on-line de acomodação entre processamento e armazenamento de acordo com a quantidade de ativação disponível para cada tipo de sujeito. Pausas entre sentenças podem mostrar a necessidade de acomodação, mas em um estágio posterior.

A pausa é um dos fatores prosódicos importantes na linguagem, representando cerca de 40 a 50\% do tempo de elocução na fala espontânea (Cazanave-Delyfer 1988:223). Analisando a influência da pausa e sua duração na interpretação de frases ambíguas, Cazanave-Delyfer verificou que, no nível perceptual, a duração da pausa por si só pode determinar uma das interpretações, a despeito dos outros elementos prosódicos. A partir de gravações de frases potencialmente ambíguas como I'd like you to meet my aunt Tessie - com uma interpretação (a), em que aunt Tessie é um grupo nominal, portanto Tessie é o nome da minha tia, e com uma interpretação (b), em que Tessie é um vocativo, portanto é Tessie que vai encontrar minha tia - esse autor manipulou a duração de pausas entre aunt e Tessie nos dois tipos de gravação. À medida que a duração da pausa nas sentenças com a interpretação (a) aumentava, mais os sujeitos davam a ela a interpretação (b); nas sentenças com a interpretação (b), ao contrário, quanto menor a duração da pausa, mais os sujeitos tenderam a interpretá-la com o sentido de (a).

Apesar de sua importância prosódica, existe uma grande variação idiossincrática no uso da pausa e na relação entre pausas silenciosas e preenchidas (Cruttenden 1986; Kaiki \& Sagisaka 1992; van Donzel \& Koopmans-van Beinum 1996; Lee \& Lee 1996). A previsão dos modelos lingüísticos de que as pausas ocorrem entre fronteiras de constituintes maiores, como entre orações e entre sujeito e predicado (Grosjean, Grosjean \& Lane 1979; Cruttenden 1986:37; van Donzel \& Koopmans-van Beinum 1996:1029), não se confirma em vários estudos. Lee \& Lee (1996), analisando as características das pausas na leitura oral em coreano, verificaram que os intervalos de silêncio intra-sentenciais não apareceram em fronteiras sintáticas maiores, mas dependeram principalmente do tamanho e da complexidade sintática da sentença. Tal fato também foi observado por Grosjean et al. (1979) em experimentos com leituras em língua inglesa. Em um estudo em holandês, van Donzel \& Koopmans-van Beinum (1996) concluem que as possibilidades de tipo de pausa e de sua localização no discurso são bastante vastas e, portanto, a escolha da estratégia específica é dependente do sujeito. Tais resultados, no entanto, não negam que a informação sintática tenha algum valor na predição da distribuição de pausas - os estudos de Grosjean et al. (1979), por exemplo, mostram que ela prediz eficazmente as pausas quando as 
sentenças e os constituintes estão balanceados - mas levantam a hipótese de que outras bases organizacionais podem estar operando no desempenho lingüístico.

Além das diferenças individuais relativas ao uso e à localização de pausas, alguns sujeitos apresentam taxa de velocidade de fala mais alta que outros. Existem evidências de que a variação na duração da pausa é um dos fatores que provocam as diferenças na velocidade da fala (Crystal \& House 1982:705; van Donzel \& Koopmans-van Beinum 1996:1029). Resultados preliminares de Crystal \& House (1982), sobre um estudo de pausas em leituras orais de textos em inglês, indicaram que os sujeitos de leitura rápida fizeram menos pausas e pausas mais curtas que os sujeitos de leitura lenta.

É importante, então, examinar se essas questões podem ser parcialmente explicadas pela capacidade de memória de trabalho de falantes do português. Se assim for, na tarefa de reading span, os sujeitos de span alto, tendo uma capacidade de memória de trabalho maior, não devem ter necessidade de fazer pausas muito longas e, portanto, devem levar menos tempo na elocução das frases que os sujeitos de span baixo. Além disso, as pausas realizadas pelos sujeitos de span alto devem ser mais coerentes com as pausas que forem mais previsíveis, mostrando menos perturbação no processamento que os sujeitos de span baixo.

A teoria de Just \& Carpenter (1992) diz respeito apenas à compreensão da linguagem, não contemplando outros processos, como a produção. Entretanto, como a leitura em voz alta envolve além da fluência na articulação da fala, a decodificação da sentença impressa e compreensão da mensagem subjacente (Daneman, 1991), é possível supor que a tarefa envolvida no teste do reading span apresente, ela própria, os efeitos das diferenças individuais de capacidade de memória de trabalho. De fato, experimentos realizados por Daneman \& Green (1986) e Daneman (1991) sobre a influência da capacidade de memória de trabalho na produção da linguagem mostraram que o teste de reading span, apesar de não apresentar correlação com várias tarefas destinadas a medir a fluência na produção da linguagem, foi eficiente com tarefas relacionadas à leitura em voz alta.

\section{O EXPERIMENTO}

O objetivo do experimento foi investigar como a capacidade de memória de trabalho restringe a habilidade individual de produção oral da linguagem. A partir da gravação da tarefa de Reading span adaptada ao português brasileiro, foram analisados os tempos de elocução de cada frase e as pausas silenciosas produzidas dentro das sentenças, assim como a localização dessas pausas com relação aos constituintes frasais.

\section{Método}

Sujeitos

Trinta e oito alunos da Universidade Estadual de Campinas (Unicamp), todos falantes nativos do português brasileiro, participaram voluntariamente do experimento, que teve duração de aproximadamente $20 \mathrm{~min}$. 


\section{Material}

A tarefa de Reading span, adaptada ao português brasileiro de acordo com a descrição do original (Daneman \& Carpenter 1980), contém 60 sentenças não relacionadas, compostas de 13 a 16 palavras, tais como

Além dos soldados, havia garotos curiosos a assistir o tiroteio, por isso continuei lutando.

Uma grande ventania forçava a porta da frente da casa-grande, a neblina entrava pela janela.

As frases (ver relação completa no apêndice) terminam com palavras de três sílabas, do tipo CVCVCV, paroxítonas, de classes gramaticais diferentes, selecionadas a partir do programa Listas (Fonêmico), com contagem de frequiência entre 10 e 50 nos dados do Projeto NURC (ver Albano et al. 1995, 1999). Os substantivos e adjetivos não são flexionados em gênero ou número e somente as formas nominais dos verbos são utilizadas. Não são encontradas no mesmo grupo frases cujas palavras finais rimem ou estabeleçam algum tipo de relação de sentido convencional.

Cada frase está disposta em uma única linha, ao centro de um cartão de $15 \mathrm{x}$ $20 \mathrm{~cm}$. As sentenças são organizadas em cinco níveis (a começar pelo nível 2), com três grupos cada, contendo duas, três, quatro, cinco ou seis sentenças; ou seja, o nível 2 contém três grupos com duas sentenças cada, o nível 3 contém três grupos com três sentenças cada, e assim sucessivamente até o nível 6, contendo três grupos com seis sentenças cada (ver apêndice). Para marcar o início e o fim de cada grupo são inseridos cartões em branco.

\section{Procedimento}

A tarefa do sujeito consistiu em ler em voz alta cada sentença, em ritmo normal, e, ao final de cada grupo (i.e. ao aparecer um cartão em branco), evocar as palavras finais de cada sentença na ordem em que foram apresentadas. Por exemplo, após ler as sentenças acima, que fazem parte de um grupo do nível 2, e que foram apresentadas nessa ordem, os sujeitos tinham que evocar lutando e janela. Antes do teste, os sujeitos foram treinados com grupos de nível 2 e avisados que o número de sentenças por grupo, na tarefa real, iria aumentar ao longo do teste. A apresentação dos cartões foi feita pelo experimentador apenas pelo tempo necessário para a leitura da sentença, i.e., tão logo o sujeito terminava de ler uma frase, a seguinte já era apresentada, de forma a evitar oportunidade para o estabelecimento de relações entre as palavras.

$\mathrm{O}$ reading span do sujeito, conforme proposto por Daneman \& Carpenter, foi determinado pelo nível mais alto em que acertou pelo menos dois dos três grupos. Por exemplo, o sujeito que acertou pelo menos dois dos três grupos do nível 2, teve seu reading span igual a 2; aquele que acertou apenas um dos três grupos do nível 3, também teve reading span igual a 2 . Diferentemente do procedimento usado na aplicação do teste original, nesta versão todos os sujeitos realizaram a tarefa completa, i.e., leram as 60 frases e tentaram evocar as palavras de cada grupo. No original, a tarefa se encerra quando o sujeito não consegue acertar dois dos três grupos de algum 
nível. Além disso, para permitir a análise dos efeitos da capacidade de memória de trabalho na produção oral de cada indivíduo, a tarefa foi gravada.

O teste foi realizado na sala acusticamente tratada do Laboratório de Fonética Acústica e Psicolingüística Experimental (LAFAPE), utilizando-se um gravador Gradiente, de 3 cabeçotes, estéreo, e fitas Sony, type II high bias UX, para evitar ruídos externos e permitir a análise acústica realizada no espectrógrafo CSL 50, da Kay Elemetrics Co., conectado a um gravador Tascam 202 MK II.

\section{ANÁLISE DOS DADOS}

Dos 38 sujeitos que fizeram a tarefa do reading span, analisamos as 60 frases produzidas por cinco sujeitos com capacidade de memória de trabalho de nível 4 e cinco com capacidade de nível 2, tratados a partir de agora como sujeitos de alto e baixo spans, respectivamente. As gravações das 60 frases de cada sujeito foram digitalizadas e a duração dos tempos totais das frases, bem como dos intervalos de silêncio, examinados através da forma de onda e espectrograma de banda larga, em duas janelas sincronizadas, com uma taxa de amostragem de $10 \mathrm{KHz}$.

A medida da duração da frase foi feita a partir do onset da vogal inicial da primeira palavra até o offset da vogal final da última palavra. Para determinar a duração das pausas seguidas de surdas, como /p/, /k/ e /t/, subtraímos do tempo total de aparente pausa silenciosa a média de duração de cada surda em outros ambientes produzidos pelo sujeito (pelo menos três eventos). Seguimos o mesmo procedimento para cada sujeito.

A classificação das pausas foi estabelecida com base em dois critérios. Por um lado, distinguimos pausas de curta e longa duração. Para determinar o limite entre pausas longas e curtas, consideramos o tempo médio de duração das consoantes surdas produzidas por cada sujeito individualmente, medidas em ambientes sem pausa, e acrescentamos mais $20 \%$ desse valor. Assim, para cada um dos 10 sujeitos, foi estabelecido um valor de corte que variou de $107,60 \mathrm{~ms}$ a $140,88 \mathrm{~ms}$.

Por outro lado, reconhecida a relação entre pausas e fronteiras sintáticas (ver, por exemplo, Ford 1982), distinguimos entre as pausas que ocorreram em uma fronteira sintática habitual, e as que ocorreram fora dessas fronteiras. São exemplos do segundo caso:

O rosto imóvel não / deixava transparecer o que sentia, trancado num silêncio duro e parado.

Este último era um animal todo negro, de / sagacidade espantosa, grande e de rara beleza. 
As pausas foram classificadas em esperadas e inesperadas, de acordo com a sua duração ou local de ocorrência, como explicado acima. A Tabela 1 resume esses critérios:

\begin{tabular}{lcc}
\hline & curta & Longa \\
\hline na fronteira sintática & esperada & Inesperada \\
fora da fronteira sintática & inesperada & Inesperada \\
\hline
\end{tabular}

Tabela 1: Classificação das pausas

Em seguida, as pausas foram reclassificadas em previsíveis - pausas entre constituintes aceitáveis, com duração curta ou longa - e não previsíveis - pausas entre constituintes não aceitáveis (Tabela 2).

\begin{tabular}{lcc}
\hline & curta & Longa \\
\hline na fronteira sintática & previsível & previsível \\
fora da fronteira sintática & não previsível & não previsível \\
\hline
\end{tabular}

Tabela 2: Reclassificação das Pausas

A análise estatística ${ }^{1}$ foi realizada usando-se o programa estatístico SAS 6.12, e os dados foram organizados segundo: (1) tempo total de produção das frases, onde foram consideradas todas as 60 frases do teste de cada sujeito (perfazendo um total de 300 sentenças em cada grupo de sujeitos), incluindo as frases com perturbações de ordem não fonético-fonológicas, como engasgos, repetições, eliminação ou acréscimo de palavras; (2) tempo depurado de produção $\boldsymbol{I}$, sem considerar as frases com problemas de engasgos, repetições etc.; (3) tempo depurado de produção II, sem as frases com problemas de engasgos, etc. e sem as pausas silenciosas; e (4) tempo total das pausas silenciosas. A partir dos resultados dos quatro tempos acima, os dados foram normalizados, eliminando-se sete outliers: três do grupo de sujeitos com span alto e quatro do grupo de sujeitos com span baixo. Os tipos de pausa foram analisados separadamente, através do Programa de Estatística e Análise de Dados para Saúde Pública, Epi Info 6, versão 6.02.

Para verificação do tempo de produção das sentenças, não consideramos as frases com engasgos e perturbações do gênero (isto é, para cada frase privilegiamos seu tempo depurado de produção I), uma vez que tais problemas ocorreram de forma e com duração bastante variadas entre os vários sujeitos. O tempo total de produção das frases, em que estão incluídos os tempos dessas sentenças com engasgos e outros problemas de ordem não fonético-fonológicos, não apresentou correlação com a capacidade de memória de trabalho.

${ }^{1}$ Agradecemos ao Paulo Rehder e a Rubens Costa Lima pela prestimosa ajuda na análise estatística e interpretação dos resultados. 


\section{RESULTADOS E DISCUSSÃO}

Eliminadas as sentenças com engasgos, verificamos que os sujeitos com span alto levaram menos tempo para ler as sentenças do teste que os sujeitos com span baixo $\left(F_{(1,506)}=4,07 ; p=0,04\right)$, mas a diferença entre os tempos de duração das sentenças não se manteve estatisticamente significativa quando foram retirados os tempos de duração das pausas silenciosas $(\mathrm{p}=0,18)$, conforme mostra a Tabela 3.

\begin{tabular}{|c|c|}
\hline Tipo & Capacidade de Memória de trabalho \\
\hline & Baixa \\
\hline tempo total de produção das frases & 5,21 \\
\hline $\begin{array}{l}\text { tempo depurado de produção I (sem } \\
\text { engasgos e outros) }\end{array}$ & $5,02 *$ \\
\hline $\begin{array}{l}\text { tempo depurado de produção II (sem } \\
\text { engasgos e outros e sem pausas) }\end{array}$ & 4,93 \\
\hline tempo total das pausas silenciosas & $0,110 *$ \\
\hline
\end{tabular}

Tabela 3: Média dos tempos (em segundos) de duração das frases e pausas, de acordo com a capacidade de memória de trabalho dos sujeitos

Esses resultados indicam que a diferença na velocidade da produção da fala entre os sujeitos com capacidade de memória de trabalho alta e baixa pode estar relacionada a um maior tempo na duração das pausas feitas pelos sujeitos de span baixo $\left(F_{(1,591)}=5,96 ; p=0,01\right)$, confirmando o que já foi apontado em outros estudos (Crystal \& House 1982; van Donzel \& Koopmans-van Beinum 1996).

Os resultados foram inconclusivos quando considerados os tempos de produção das sentenças nos diferentes níveis do teste de reading span, não sendo possível detectar nenhum tipo de perturbação específica que tenha aumentado à medida que a tarefa requereu uma maior demanda. Entretanto, esse efeito pode ser observado através da análise quantitativa das sentenças sem pausas, nos diversos níveis de reading span (Tabela 4), produzidas em maior número pelos sujeitos de span alto $\left(\chi^{2}=4,80 ; p=0,02\right)$. Não haver uma diferença significativa no nível $2(\mathrm{p}=0,29)$ é coerente com os spans dos sujeitos: como, nesse nível, a demanda é compatível com as capacidades de memória de trabalho de ambos os tipos de sujeito, a facilidade ou dificuldade de executar a tarefa não deve ser muito diferente. No nível 3, entretanto, enquanto os sujeitos com baixo span já não tinham recursos suficientes para manter na memória as palavras finais e processar a sentença simultaneamente, e portanto produziram menos sentenças sem pausas $\left(\chi^{2}=4,36 ; \mathrm{p}=0,03\right)$, os sujeitos de alto span mantiveram seu desempenho porque a demanda continuava compatível com sua capacidade de memória de trabalho. No nível 4, é provável que os sujeitos de span baixo, já tendo aprendido que não tinham condições de memorizar as palavras requeridas, dedicaram maior atenção à computação da frase, não diferindo significativamente, portanto, dos sujeitos de span alto $\left(\chi^{2}=2,79\right.$; $\mathrm{p}=0,09)$. Nos níveis 5 e 6 , os sujeitos passam a ter novamente condições semelhantes - 
nesse caso, sem recursos suficientes para executar a tarefa de armazenamento portanto não diferiram nos seus resultados $(\mathrm{p}=0,37 \mathrm{e} \mathrm{p}=0,71$, respectivamente).

\begin{tabular}{lcc}
\hline nível & capacidade de memória de trabalho \\
\hline & alta & Baixa \\
2 & 14 & 10 \\
3 & $23^{*}$ & $12^{*}$ \\
4 & 39 & 29 \\
5 & 33 & 29 \\
6 & 38 & 40 \\
Total & $147^{*}$ & $120^{*}$ \\
\hline
\end{tabular}

Nota: $* \mathrm{p}<0.05$

Tabela 4: Número de sentenças sem pausas, por nível e capacidade de memória de trabalho do sujeito

A análise estatística das diferenças no número das pausas (Tabela 5) mostra que os sujeitos não diferiram significativamente no número total de pausas que realizaram, quer quando foram consideradas esperadas quer quando foram consideradas inesperadas. A análise das frases com engasgos também não mostrou diferenças estatisticamente significativas entre os sujeitos. Para quaisquer desses itens, não foi possível observar qualquer perturbação específica entre os sujeitos ao longo da tarefa. Entretanto, o fato de os resultados não serem estatisticamente significativos não representa que o efeito necessariamente não exista. É possível que o número de observações tenha sido insuficiente para mostrar claramente o que outros dados estão indicando.

\begin{tabular}{lcc}
\hline tipo & capacidade de memória de trabalho \\
\hline & alta & Baixa \\
pausa esperada & 37 & 48 \\
pausa inesperada & 75 & 96 \\
total de pausas & 112 & 144 \\
total de frases com engasgos & 41 & 44 \\
\hline
\end{tabular}

Tabela 5: Número de eventos de acordo com a memória de trabalho do sujeito

O tempo de duração das pausas, no entanto, revelou diferenças entre os sujeitos. Modificando-se a aplicação dos critérios que usamos para classificar o tempo de duração das pausas, de forma a distingui-las entre previsíveis (aquelas que ocorreram entre constituintes aceitáveis - com duração curta ou longa) e não previsíveis (somente aquelas que ocorreram entre constituintes não aceitáveis) (ver Tabela 2 acima), observamos que, enquanto os sujeitos de span alto não apresentaram diferença significativa entre os tempos de duração das pausas previsíveis e não previsíveis, os de span baixo fizeram pausas não previsíveis mais longas que as previsíveis $\left(\mathrm{F}_{(1,141)}=6,99\right.$; $\mathrm{p}=0,008$ ) (Tabela 6). Além disso, apesar de o tempo de duração das pausas previsíveis não ter sido estatisticamente diferente entre os sujeitos de spans alto e baixo $(\mathrm{p}=0,82)$, o 
das pausas não previsíveis tendeu a ser mais curto para os sujeitos com span alto $\left(\mathrm{F}_{(1,50)}=3,13 ; \mathrm{p}=0,07\right)$.

\begin{tabular}{lcc}
\hline \multicolumn{1}{c}{ tipo de pausa } & Capacidade de Memória de trabalho \\
\hline & Alta & Baixa \\
previsíveis & 0,210 & $0,215^{*}$ \\
não previsíveis & $0,214^{+}$ & $0,309 *^{+}$ \\
\hline Nota: $* p=0,008 ;{ }^{+} p=0,07$ & &
\end{tabular}

Tabela 6: Média dos tempos (em segundos) de duração das pausas, de acordo com a capacidade de memória de trabalho dos sujeitos

\section{CONCLUSÃO}

Conforme nossas hipóteses, os sujeitos de alto span levaram menos tempo na produção das sentenças do teste de reading span que os sujeitos de baixo span. Os dados indicam que essa diferença foi devida ao tempo de duração das pausas: mais curtas nos sujeitos de span alto. A quantidade de sentenças sem pausas produzidas pelos sujeitos de span alto também foi maior que a dos outros sujeitos, e a análise por nível sugere que os sujeitos de span baixo sofreram mais o efeito da demanda crescente ao longo da tarefa que os sujeitos de baixo span. Esses resultados corroboram a idéia de que a qualidade da produção da linguagem, assim como Just \& Carpenter (1992) observaram para a compreensão, também sofre influência da capacidade de memória de trabalho dos sujeitos.

\section{REFERENCIAS}

ALBANO, E., Moreira,A., Aquino, P., Silva. \& Kakinohana, R. (1995). Segment Frequency and word structure in Brazilian Portuguese, Proceedings of the International Congress of Phonetic Science, 95, 3, 1995, p.346-9.

ALBANO, E., Moreira, A, Aquino, P. \& Silva, A. \& Kakinohana, R. (1999). Um conversor ortográficofônico e uma notação prosódica mínima para síntese de fala em língua portuguesa. In Scarpa, E.M. (org.) Estudos de Prosódia, Editora da UNICAMP, Campinas, 1999, p.85-109.

BADDELEY, A.D. (1986). Working Memory. New York: Oxford University Press.

CAZANAVE-DELYFER, M.-Th. (1988). Phénomènes de pause. R.P.A., 87-88-89: 223-246.

CRUTTENDEN, A. (1986). Intonation. Cambridge: Cambridge University Press.

CRYSTAL, T.H. \& House, A.S. (1982). Segmental durations in connected speech signals: preliminary results. Journal of the Acoustical Society of America 72(3):705-716.

DANEMAN, M. (1991). Working Memory as a Predictor of Verbal Fluency. Journal of Psycholinguistic Research 20(6): 445-464. 
DANEMAN, M. \& Carpenter, P.A. (1980). Individual differences in working memory and reading. Journal of Verbal Learning and Verbal Behavior 19: 450-466.

. (1983). Individual differences in integrating information between and within sentences. Journal of Experimental Psychology: Learning, Memory, and Cognition 9(4): 561-584.

DANEMAN, M. \& Green, I. (1986). Individual differences in comprehending and producing words in context. Journal of Memory and Language 25:1-18.

FERREIRA, F. \& Clifton, C. (1986). The independence of syntactic processing. Journal of Memory and Language 25:348-368.

FORD, M. (1982). Sentence planning units: implications for the speaker's representation of meaningful relations underlying sentences. In: J. BRESNAN (ed.) The mental representation of grammatical relations. Cambridge, MA: The MIT Press.

FODOR, J. (1983). Modularity of mind. Cambridge, Mass.: The MIT Press.

GROSJEAN, F., Grosjean, L. \& Lane, H. (1979). The patterns of silence: performance structures in sentence production. Cognitive Psychology 11:58-81.

JUST, M.A. \& Carpenter, P.A. (1992). A capacity theory of comprehension: individual differences in working memory. Psychological Review 99(1): 122-149.

KAIKI, N. \& Sagisaka, Y. (1992). Pause characteristics and local phrase-dependency structure in Japanese. Proceedings of the International Congress of Spoken Language Processing, p. 357-360.

KING, J. \& Just, M.A. (1991). Individual differences in syntactic processing: the role of working memory. Journal of Memory and Language 30: 580-602.

LEE, Y-J \& Lee, S-h (1996). On phonetic characteristics of pause in the Korean read speech. Proceeding of the International Congress of Spoken Language Processing, 118-120.

MIYAKE, A., Carpenter, P.A. \& Just, M.A. (1995). Reduced resources and specific impairments in normal and aphasic sentence comprehension. Cognitive Neuropsychology 12(6): 651-679.

van DONZEL, M.E. \& Koopmans-van Beinum, F.J. (1996). Pausing strategies in discourse in Dutch. Proceeding of the International Congress of Spoken Language Processing, p. 1029-1032. 


\section{APÊNDICE}

Frases utilizadas na tarefa de Reading Span, versão utilizada neste trabalho, por nível e grupo.

\section{Nível 2}

Grupo 1:

1. Além dos soldados, havia garotos curiosos a assistir o tiroteio, por isso continuei lutando.

2. Uma grande ventania forçava a porta da frente da casa-grande, a neblina entrava pela janela.

Grupo 2:

1. Quando regou pela última vez as suas orquídeas, percebeu que estava com medo de ficar sozinho.

2. Todos queriam brincar bebê, mas conseguiram porque ele ainda não tinha mamado.

Grupo 3:

1. No interior, pelo menos, não tenho que pagar aluguel e minha família visualiza algum futuro.

2. De repente varou na escuridão uma espécie de gargalhada de arrepiar e senti algo me batendo.

\section{Nível 3:}

Grupo 1:

1. A única evidência nesse momento, a única mesmo, era ela que vinha em sua direção pulando.

2. Porém nesse universo pequeno só haveria ele e o seu adversário, a revolução e o regime.

3. Falaram também que seus carros só chegaram aqui depois de adaptados e o negócio fechado.

Grupo 2:

1. Entretanto, o que mais distraiu sua atenção foi uma fila de formigas a caminho da cebola.

2. São jóias preciosas com mecanismo a quartzo, feitos com dois diamantes do mesmo tamanho.

3. Quando então abriu os olhos, tentando entender alguma coisa, notou que estava sendo puxado.

Grupo 3:

1. Meu grupo lançava-se outra vez pelo espaço, sempre em busca de realizar mais um desejo.

2. Foram os primeiros a tornar muito mais simples as estruturas para a construção do telhado.

3. O táxi subiu o morro, de onde as crianças puderam vislumbrar aquele monumento tão falado.

\section{Nível 4:}

Grupo 1:

1. Deviam ser umas nove da noite quando viu o homem chegar e entrar encostado na parede.

2. Cinco adolescentes da oitava série e três da sétima receberam nota zero por estarem colando.

3. Pretendo retribuir o apoio que recebi vendendo a nossa mercadoria por um preço bem mais barato.

4. Tinha certeza de que o tio Fernando recuperaria a memória depois de repousar no caminho. Grupo 2:

1. No muro chácara do vovô apareceu uma coisa parecida com um grande pé de batata.

2. Aí mora uma mulher cega com várias crianças, todos seus filhos, exceto o menino levado.

3. Disparou para a varanda tão rápido quanto podia, mal tocando com as patinhas no tecido.

4. A senhora de preto continuou sentada e continuou a discorrer sobre aquela história chocante. Grupo 3:

1. Em cinco anos, todos já terão condições suficientes de comprar pelo menos um bezerro.

2. Tinha que descansar, ou poderia ficar tonto e perder a visão na hora que fosse chamado.

3. Com esse instrumento, eles poderão pagar tudo em dia e recuperar os aparelhos da cozinha.

4. Ele conhecia todo o plano verdadeiro, mas nunca entendi bem por que continuava negando.

\section{Nível 5:}

Grupo 1:

1. Este último era um animal todo negro, de sagacidade espantosa, grande e de rara beleza.

2. A prova estava espalhada em pedaços pelo piso do porão: o meu quadro tinha sido serrado.

3. Os golfinhos sumirão se não tomarem medidas severas de restrição ao turismo marinho.

4. Como a fome era enorme, Bento preparou uma omelete deliciosa com queijo, ovo e salada.

5. O encontro de Cristiana com os boêmios teria sido no Hotel Avenida, mas estava chovendo.

Grupo 2:

1. Nenhuma pessoa de bom senso vai se deixar enganar pelas aparências e comprar um carro batido. 
2. Asse em forno quente, deixe dourar um pouco e acrescente o cogumelo em uma única camada.

3. Derramou bastante água num canteiro de lírios e suspirou, quando viu que um deles tinha secado.

4. Então nós vimos quatorze anõezinhos cavando a terra à procura de minhocas para dar à galinha.

5. Achamos uma mulherzinha de coque e vestido pretos e um homem gordo de bermuda e sapato.

Grupo 3:

1. Um grande pássaro colorido pousou na fonte da praça e, por alguns minutos, ficou se banhando.

2. Não conseguiu completar o álbum porque, na última página, ainda estava faltando uma figura.

3. Nossos brinquedos para seu bebê são mais criativos e seguros, uma mistura de tecido e borracha.

4. Mas amanhã mesmo posso perder tudo que tenho, por isso exijo que vocês continuem mentindo.

5. Acabei precisando de um microcomputador porque o serviço já estava ficando muito pesado.

\section{Nível 6:}

Grupo 1:

1. Diariamente, antes de fechar a barbearia, a faxineira limpava tudo e deixava o banheiro lavado.

2. Marcos fez um gesto de cabeça significativo, indicando que já era hora de iniciarem o desenho.

3. Durante o processo de revisão, qualquer discurso - simples ou rebuscado - pode ser mexido.

4. Como estávamos com fome, comemos um pedaço de queijo e boa porção de doce de banana.

5. Pela aceitação imediata e resultados positivos, o seu projeto pode ser considerado um sucesso.

6. Voltamos a reanimar o pobre seminarista, que estava, outra vez, cheio de tristeza e chorando.

Grupo 2:

1. Somente quando tiver terminado seu serviço, venha me procurar para ver se lhe dou a farinha.

2. Antes mesmo de ir à polícia, contou tudo em um depoimento impressionante, grave e direto.

3. Naquela semana, o governador em pessoa fez questão de acertar todos os detalhes da corrida.

4. Estava num aposento, com janelas para uma rua movimentada, cheio de lixo e um balde furado.

5. Eles percorreram inúmeros botecos do Bexiga, dos Jardins e da Lapa, dia e noite, sempre bebendo.

6. O rosto imóvel não deixava transparecer o que sentia, trancado num silêncio duro e parado.

Grupo 3:

1. Até mesmo o vento parece soar diferente nos picos, badalando sinos, fazendo muito barulho.

2. Desde bem pequeno, estavam patentes a docilidade e o instinto maternal do meu cachorro.

3. Logo que vi tal aparição, a coragem e a valentia - que sempre procurei ter - foram sumindo.

4. Nem sempre o político que recebe mais dinheiro consegue ser o candidato mais votado.

5. O acidente foi grave, mas as conseqüências nem tanto, só tive alguns arranhões na barriga.

6. Não queria deixar para a nova cooperativa nem a mandioca nem o milho que havia colhido. 